\title{
Circulating levels of neurotrophic factors are unchanged in patients with Parkinson's disease
}

\author{
Os níveis circulantes de fatores neurotróficos não estão alterados em pacientes com \\ doença de Parkinson
}

Natalia Pessoa Rocha ${ }^{1,2,3}$, João Paulo Sampaio Ferreira², Paula Luciana Scalzo ${ }^{4}$, Izabela Guimarães
Barbosa², Mariana Soares de Souza ${ }^{5}$, Paulo Pereira Christo ${ }^{5}$, Helton José Reis ${ }^{3}$, Antonio Lucio Teixeira ${ }^{1,2}$

\begin{abstract}
There is great evidence linking neurotrophic factor (NF) dysfunction with Parkinson's disease (PD) pathophysiology. This study was conducted to evaluate plasma levels of NFs and their possible associations with clinical symptoms in PD. For this purpose, 40 PD patients and 25 controls were subjected to a clinical evaluation and peripheral blood draw. Plasma levels of brain-derived neurotrophic factor (BDNF), pro-BDNF, neurotrophin 3, neurotrophin 4, nerve growth, glial cell line-derived neurotrophic factor and ciliary neurotrophic factor were measured by enzyme-linked immunosorbent assay. There was no significant difference between PD patients and controls regarding the plasma levels of the evaluated NFs. In addition, NF levels were not associated with disease duration, degree of motor or functional impairment, cognitive performance or severity of depressive symptoms. In conclusion, although NFs may play relevant roles in the pathophysiology of PD, the circulating levels of these molecules are not necessarily changed in patients with PD.
\end{abstract}

Keywords: Parkinson's disease; nerve growth factors; depression; biomarkers; cognition.

\section{RESUMO}

Há evidências de que alteracões nas ações exercidas por fatores neurotróficos (FNs) estejam associadas à fisiopatologia da doença de Parkinson (DP). O presente estudo foi conduzido para avaliar os níveis plasmáticos de FNs e suas possíveis associações com sintomas clínicos na DP. Para este fim, 40 pacientes com DP e 25 controles foram submetidos à avaliação clínica e coleta de sangue periférico. Os níveis plasmáticos do fator neurotrófico derivado do cérebro (BDNF), pro-BDNF, neurotrofina 3, neurotrofina 4, fator de crescimento do nervo, fator neurotrófico derivado da glia e fator neurotrófico ciliar foram avaliados por ensaio de imunoadsorção enzimática. Não houve diferença significativa entre pacientes com DP e controles quanto aos níveis plasmáticos dos FNs avaliados. Além disso, não encontramos associação entre os níveis dos FNs e duração da doença, grau de comprometimento motor ou funcional, desempenho cognitivo e gravidade dos sintomas depressivos. Em conclusão, embora os FNs possam desempenhar papéis relevantes na fisiopatologia da DP, os níveis circulantes dessas moléculas não estão necessariamente alterados em pacientes com DP.

Palavras-chave: doença de Parkinson; fatores de crescimento neural; depressão; biomarcadores; cognição.

Parkinson's disease (PD) is the second most frequent neurodegenerative disease and the leading cause of parkinsonism. Parkinsonism is defined by the presence of bradykinesia and at least one of the following symptoms: rigidity, resting tremor and postural instability. The pathophysiology PD is defined as the result of the loss of dopaminergic neurons in the substantia nigra pars compacta and the accumulation of alpha-synuclein aggregated in the remaining neurons ${ }^{1}$. The

\footnotetext{
${ }^{1}$ The University of Texas Health Science Center at Houston, McGovern Medical School, Department of Psychiatry and Behavioral Sciences, Neuropsychiatry Program, Houston, TX, USA;

2Universidade Federal de Minas Gerais, Faculdade de Medicina, Laboratório Interdisciplinar de Investigação Médica (LIIM), Belo Horizonte MG, Brasil;

${ }^{3}$ Universidade Federal de Minas Gerais, Instituto de Ciências Biológicas, Laboratório de Neurofarmacologia, Belo Horizonte MG, Brasil;

${ }^{4}$ Universidade Federal de Minas Gerais, Instituto de Ciências Biológicas, Laboratório de Neurobiologia, Belo Horizonte MG, Brasil;

${ }_{5}^{5}$ Santa Casa de Belo Horizonte Hospital, Departamento de Neurologia e Neurocirurgia, Belo Horizonte MG, Brasil.
}

Correspondence: Natalia Pessoa Rocha; Laboratório Interdisciplinar de Investigação Médica da FCUFMG; Av. Prof. Alfredo Balena, 190 / Sala 281;

30130-100 Belo Horizonte MG, Brasil; E-mail: npessoarocha@gmail.com

Conflict of interest: There is no conflict of interest to declare.

Support: This study was funded by Fundação de Amparo à Pesquisa do Estado de Minas Gerais (FAPEMIG), Conselho Nacional de Desenvolvimento Científico e Tecnológico (CNPq) and Coordenação de Aperfeiçoamento de Pessoal de Nivel Superior (CAPES).

Received 22 November 2017; Received in final form 17 January 2018; Accepted 22 January 2018. 
diagnosis of the disease is clinical, based on the presence of the cardinal motor symptoms and the exclusion of other causes of parkinsonism, including vascular and drug-induced parkinsonism. In recent years, several nonmotor symptoms have been recognized as major components of the disease ${ }^{1,2}$.

Neurotrophic factors (NF[s]) are soluble polypeptides that are involved in the development, growing, functioning and regulation of neurons and neuron-supporting cells. They usually act through membrane-bound receptors with intrinsic tyrosine kinase activity, determining the activation of transcription factors and the expression of specific genes. These genes encode proteins involved in regulating neuronal survival, differentiation and plasticity ${ }^{3,4}$. Parkinson's disease is an age-related disease ${ }^{5}$ and abnormal NF support during aging seems to play a major role in the pathophysiology of neurodegenerative diseases, such as Alzheimer's disease and PD.

Due to their intrinsic properties of promoting neuronal and glial cell regeneration, NFs became a subject of research in the treatment of neurodegenerative diseases. Interestingly, some drugs used clinically to treat Alzheimer's disease (memantine) and PD (levodopa, rasagiline, pramipexole, ropinirole) share the property of modulating NF levels in the brain regions involved in the pathophysiology of the respective disease ${ }^{3}$. In PD, although the strategies were successful in inducing protection of dopaminergic neurons in vitro and motor recovery in preclinical models of the disease, very limited success has been obtained in clinical studies ${ }^{6}$.

Evidence linking NF dysfunction with PD came from postmortem studies that reported reduced levels or expression of brain-derived neurotrophic factor $(\mathrm{BDNF})^{7,8}$, nerve growth factor $(\mathrm{NGF})^{7}$, glial cell line-derived neurotrophic factor $(\mathrm{GDNF})^{8}$ and ciliary neurotrophic factor $(\mathrm{CNTF})^{8}$ in the substantia nigra of people who suffered from PD. Moreover, circulating levels of $\mathrm{NGF}^{9}$ and $\mathrm{BDNF}^{10-14}$ were also found to be altered in the circulation of patients with PD.

Given the relevance of NFs in PD, the aim of this work was to evaluate plasma levels of NFs and their possible associations with clinical symptoms in PD.

\section{METHODS}

\section{Participants and clinical evaluation}

This study was conducted in the same cohort of patients as the study by Rocha et al. $^{15}$, and therefore included 40 patients diagnosed with PD and a group of 25 control participants of comparable age, sex, educational level and body mass index (BMI). We followed the methods of Rocha et al. ${ }^{15}$. The diagnosis of PD was based on the UK Brain Bank criteria $^{1}$. Patients were recruited from the Movement Disorders outpatient clinic, Santa Casa de Belo Horizonte Hospital, Belo Horizonte, Brazil. Control participants were recruited from the local community. Participants were excluded if they had undergone previous neurosurgery or if they had any other neurological disorder and/or cognitive decline (i.e., delirium or dementia), significant sensory impairment and active infectious or autoimmune diseases in the previous four weeks. In addition, individuals who had used corticosteroids, anti-inflammatories or antibiotics in the four weeks prior to the study were excluded. All participants provided written informed consent before admission to the study. The Research Ethics Committee of the Universidade Federal de Minas Gerais, Brazil approved this study.

All patients were evaluated with the Unified Parkinson's Disease Rating Scale (UPDRS) ${ }^{16}$, which assesses different signs and symptoms of PD. The UPDRS scores were obtained in the "on" state of the disease. The modified Hoehn and Yahr staging scale was used to establish the stage of $\mathrm{PD}^{17}$. The modified Schwab and England activities of daily living scale was used to assess the daily routines of PD patients ${ }^{16}$. All individuals were subjected to a cognitive examination, which included the Mini-Mental Status Examination ${ }^{18}$ adapted for the elderly Brazilian population ${ }^{19}$. The Mini-Mental Status Examination is a brief test for cognitive screening, comprising items from different domains such as orientation, attention, memory and language. Since impairment in executive functioning is the most common cognitive deficit in PD patients, the Frontal Assessment Battery was also used ${ }^{20,21}$. This is a brief assessment tool that evaluates executive functioning and consists of six sub-tests exploring cognitive processes related to the frontal lobes: conceptualization, mental flexibility, motor programming, sensitivity to interference, inhibitory control and environmental autonomy. In addition, all participants were evaluated using the Beck's Depression Inventory, a self-rating instrument for depressive symptoms comprising 21 items, each ranging from 0 to 3 , according to the severity of symptoms ${ }^{22}$. The Beck's Depression Inventory has been validated as a tool for depression screening and diagnosis in $\mathrm{PD}^{23,24}$.

\section{Assessment of neurotrophic factors}

Ten milliliters of blood were drawn by venipuncture in vacuum tubes containing heparin (Vacuplast, Huangyn, China) on the same day as the clinical assessment. In order to rule out any confounding factors caused by circadian rhythm, all samples were collected at the same time of the day, between 14:00-16:00. The whole blood samples were kept at room temperature and used within two hours of having been drawn. These samples were then centrifuged at $1,700 \mathrm{~g}$ for $10 \mathrm{~min}, 4^{\circ} \mathrm{C}$, twice. The plasma was collected and stored at $-70^{\circ} \mathrm{C}$ until assayed.

Plasma levels of BDNF, pro-BDNF, GDNF, NGF, CNTF, neurotrophin (NT)3 and NT4 were measured by enzyme-linked immunosorbent assay according to the procedures supplied by the manufacturer (DuoSet, R\&D Systems, Minneapolis, MN, USA). The assays were performed in duplicate, blinded 
to the clinical status of the participants. Concentrations are expressed as $\mathrm{pg} / \mathrm{mL}$. Lower detection limits for all analyzed molecules were $10 \mathrm{pg} / \mathrm{mL}$.

\section{Statistical analysis}

Association between dichotomous variables was assessed with Fisher's exact test. All variables were tested for Gaussian distribution by the Shapiro-Wilk normality test. The two groups (patients vs. controls) were compared using the Mann-Whitney U or Student's t tests when non-normally or normally distributed, respectively. Spearman's correlation analyses were performed to examine the relationship between clinical variables and plasma levels of the NFs. All statistical tests were two-tailed and were performed using a significance level of $\alpha=0.05$. Statistical analyses were performed using SPSS software version 22.0 (SPSS Inc., Chicago, IL, USA) as well as GraphPad Prism 5.0 for Windows ${ }^{\mathrm{mm}}$ (GraphPad Software, Inc., La Jolla, CA, USA)

\section{RESULTS}

\section{Sociodemographic and clinical results}

This study included 40 patients with PD and 25 controls whose clinical and demographic characteristics are shown in Table 1. Patients with PD and the controls did not differ with respect to age, sex, educational level and BMI. The control individuals showed better cognitive performance than patients with $\mathrm{PD}$, as demonstrated by the Mini-Mental Status Examination scores. In addition, PD patients were worse than controls in the programming task of the Frontal Assessment Battery. Patients with PD also had higher scores on the Beck's Depression Inventory compared with controls. This result indicates that patients with PD experience more depressive symptoms than individuals who are not diagnosed with PD.

The clinical features of PD are presented in Table 2. Patients with PD exhibited mild to moderate motor impairment as evidenced by the UPDRS, with a median Hoehn and Yahr staging of $2 \%$ and Schwab and England activities of daily living median of $80 \%$. These parameters are compatible with non-advanced PD. The great majority of PD patients included in this study (92.5\%) were taking levodopa.

\section{Plasma levels of NFs}

There was no significant difference between PD patients and controls regarding the plasma levels of the evaluated NFs (Figure). The NF levels obtained for both the patients with PD and the controls are provided in Table 3.

The NF levels were not associated with disease duration or with the degree of motor or functional impairment, as assessed by the UPDRS. Among controls, higher levels of BDNF were associated with lower severity of depressive symptoms, as assessed by the Beck's Depression Inventory (rho $=-0.547, p=0.005$ ). The same association was not found in patients with PD.

Table 1. Clinical (non-motor) and demographic features of participants included in the assessment of neurotrophic factors.

\begin{tabular}{|c|c|c|c|}
\hline Variable & Patients with PD $(n=40)$ & Controls $(n=25)$ & $\mathrm{p}$-value \\
\hline Sex (female/male) & $13 / 27$ & $6 / 19$ & $0.58^{a}$ \\
\hline Age in years (mean $\pm \mathrm{SD})$ & $68.71 \pm 10.07$ & $65.23 \pm 8.75$ & $0.20^{b}$ \\
\hline Body mass index. $\mathrm{Kg} / \mathrm{m}^{2}($ mean $\pm \mathrm{SD})$ & $26.02 \pm 3.73$ & $27.64 \pm 3.71$ & $0.09^{\circ}$ \\
\hline Educational level in years (mean \pm SD) & $4.72 \pm 2.87$ & $6.72 \pm 5.37$ & $0.16^{b}$ \\
\hline MMSE $[$ mean \pm SD (median)] & $24.00 \pm 3.99(25)$ & $27.00 \pm 3.57(29)$ & $0.001^{b}$ \\
\hline $\mathrm{FAB}[$ mean $\pm \mathrm{SD}$ (median)] & $11.49 \pm 2.99(12)$ & $12.32 \pm 3.67(13)$ & $0.28^{b}$ \\
\hline Conceptualization & $1.23 \pm 1.01(1)$ & $1.64 \pm 1.11(2)$ & $0.12^{b}$ \\
\hline Mental flexibility & $1.82 \pm 1.10(2)$ & $2.08 \pm 1.04(2)$ & $0.34^{\mathrm{b}}$ \\
\hline Programming & $1.74 \pm 0.91(2)$ & $2.24 \pm 0.83(2)$ & $0.04^{b}$ \\
\hline Sensitivity to interference & $2.26 \pm 0.94(3)$ & $1.84 \pm 1.25(2)$ & $0.21^{b}$ \\
\hline Inhibitory control & $1.41 \pm 0.88(1)$ & $1.52 \pm 1.09(1)$ & $0.73^{b}$ \\
\hline Environmental autonomy & $3.00 \pm 0.00(3)$ & $3.00 \pm 0.00(3)$ & $1.00^{\mathrm{b}}$ \\
\hline $\mathrm{BDI}[$ mean $\pm \mathrm{SD}$ (median)] & $8.64 \pm 7.58(6)$ & $2.76 \pm 3.35(1)$ & $<0.001^{\mathrm{b}}$ \\
\hline \multicolumn{4}{|l|}{ Drugs in use (frequency in \%) } \\
\hline Antihypertensive & 55 & 48 & $0.62^{a}$ \\
\hline Antidiabetic & 10 & 20 & $0.29^{a}$ \\
\hline Hypolipidemic & 10 & 24 & $0.17^{a}$ \\
\hline Levothyroxine & 10 & 4 & $0.64^{\mathrm{a}}$ \\
\hline Antidepressants & 20 & 12 & $0.51^{\mathrm{a}}$ \\
\hline
\end{tabular}


Table 2. Clinical features (motor) of patients with Parkinson's disease included in the dosage of neurotrophic factors.

\begin{tabular}{lc}
\hline Variables & Patients with PD $(n=40)$ \\
\hline Length of illness in years & $5.45 \pm 4.13(0.4-18)$ \\
[mean \pm SD (range) & $51.82 \pm 25.27(11-105)$ \\
UPDRS [mean \pm SD (range)] & $3.36 \pm 2.96(0-11)$ \\
\hline UPDRS I [mean \pm SD (range)] & $14.08 \pm 7.14(2-31)$ \\
\hline UPDRS II [mean \pm SD (range)] & $34.56 \pm 18.43(8-69)$ \\
UPDRS III [mean \pm SD (range)] & $2.44 \pm 0.69(1-4)$ \\
H\&Y [mean \pm SD (range)] & $77.95 \pm 11.96(50-100)$ \\
\hline S\&E in \% [average \pm SD (range)] & $37(92.50)$ \\
\hline Drugs in use [N (frequency in \%)] & $20(50.00)$ \\
\hline Levodopa & $7(17.50)$ \\
\hline Pramipexole & $11(27.50)$ \\
\hline Entacapone & \\
\hline Amantadine & \\
\hline
\end{tabular}

PD: Parkinson's disease; SD: standard deviation; UPDRS: unified Parkinson's disease rating scale; H\&Y: Hoehn and Yahr staging scale; S\&E: Schwab and England activities of daily living scale.

\section{DISCUSSION}

Despite several studies using different approaches having pointed out a key role of NFs in PD, we found that circulating levels of NFs (BDNF, pro-BDNF, NGF, CTNF, GDNF, NT3 and NT4) were not changed in PD patients when compared with BMI-, sex- and age-matched controls.

It is worth noting a significant dispersion in the levels of NFs, mainly in the PD group. This dispersion might explain the divergence from previous studies. For example, a series of studies found lower circulating levels of NFs in PD compared with controls ${ }^{10-14}$. Increased levels of NFs have also been described in serum ${ }^{25}$ and cerebrospinal fluid (CSF) ${ }^{26}$ of PD patients.

The dispersion in the levels of NFs might be explained by individual characteristics such as disease stage, medical comorbidities, physical activity, medications in use, disease phenotype, among others. Physical activity has been extensively linked to changes in NF levels. Not only do BDNF levels increase, but motor symptoms may also decrease in response
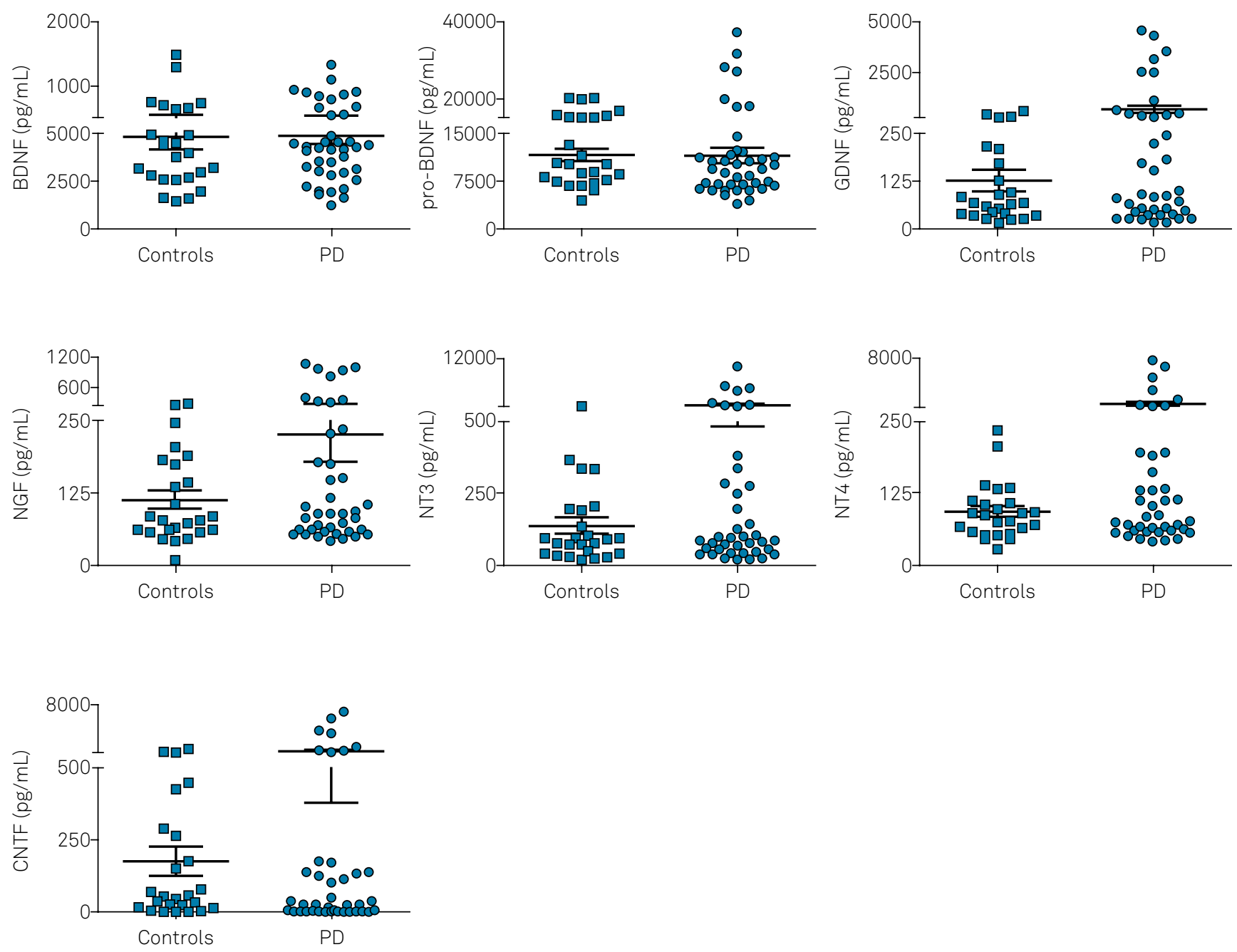

BDNF: brain-derived neurotrophic factor; CNTF: ciliary neurotrophic factor; GDNF: Glial cell line-derived neurotrophic factor; NGF: nerve growth factor; NT: neurotrophin; PD: Parkinson's disease.

Figure. Plasma concentrations of neurotrophic factors. Patients with Parkinson's disease and controls showed no statistically significant difference in the plasma levels of neurotrophic factors evaluated. 
Table 3. Plasma concentrations of neurotrophic factors evaluated in patients with Parkinson's disease and controls.

\begin{tabular}{lccc} 
Neurotrophic factor & Patients with PD $(n=40)$ & Controls $(n=25)$ & $p$-value \\
\hline BDNF & $4878.22 \pm 2786.02(4256.89)$ & $4810.83 \pm 3269.54(4025.40)$ & $0.69^{\mathrm{a}}$ \\
Pro-BDNF & $11526.15 \pm 7599.66(9423.39)$ & $11638.26 \pm 4738.97(10237.25)$ & $0.30^{\mathrm{a}}$ \\
NGF & $225.94 \pm 297.01(88.40)$ & $112.78 \pm 76.87(76.56)$ & $0.38^{\mathrm{a}}$ \\
GDNF & $661.2 \pm 1242(88.78)$ & $127.4 \pm 139.3(68.67)$ & $0.22^{\mathrm{a}}$ \\
CNTF & $630.33 \pm 1585.85(25.94)$ & $176.24 \pm 254.66(53.58)$ & $0.40^{\mathrm{a}}$ \\
NT3 & $799.00 \pm 1988.73(92.55)$ & $140.34 \pm 145.35(92.55)$ & $0.40^{\mathrm{a}}$ \\
NT4 & $697.91 \pm 1768.08(86.67)$ & $94.09 \pm 48.49(87.68)$ & $0.32^{\mathrm{a}}$ \\
\hline
\end{tabular}

Results are given in pg/mL [mean \pm standard deviation (median)]. PD: Parkinson's disease; BDNF: brain-derived neurotrophic factor; NGF: nerve growth factor: GDNF: glial cell line-derived neurotrophic factor; CNTF: ciliary neurotrophic factor; NT: neurotrophin; ${ }^{\text {a: }}$ Mann-Whitney Test.

to physical activity ${ }^{25,27,28}$. Indeed, physical activity has been proposed as a therapeutic intervention to ameliorate PD symptoms and delay PD progression. The existing data suggest an association between the increase in serum levels of BDNF and the beneficial effects of physical activity in $\mathrm{PD}^{6}$.

Regarding the disease phenotype (i.e., predominant clinical presentation), lower BDNF levels have been associated with a greater severity of depressive symptoms ${ }^{13}$ and cognitive impairment ${ }^{14}$. Corroborating these results, lower CSF levels of BNDF have also been associated with depression ${ }^{29}$, and higher CSF BDNF levels with better cognitive performance in $\mathrm{PD}^{30}$. Conversely, our independent cohort of PD patients showed that BDNF levels correlated positively with the duration of the disease and the severity of motor symptoms ${ }^{10}$. We hypothesized that lower BDNF levels in early stages of the disease may be associated with pathogenic mechanisms of PD. The increase of BDNF levels with the progression of the disease may be a compensatory mechanism in more advanced stages of $\mathrm{PD}^{10}$.

We are aware of the limitations of our study, including the sample size and the cross-sectional design of the study. The lack of information about physical activity is an important limitation for the interpretation of our results. In addition, all patients were medicated and the observed findings might also be influenced by their ongoing treatment. In contrast, the strict exclusion criteria, the selection of controls with comparable age, sex and BMI, and the comprehensive clinical evaluation can be regarded as strengths of the study.

In conclusion, although NFs may play relevant roles in the pathophysiology of PD, we did not find changes in the circulating levels of these molecules. Several factors can influence the circulating levels of NFs, and these need to be controlled to obtain meaningful pathophysiological information in PD.

\section{Acknowledgments}

The authors acknowledge the participation of volunteers in this study and are indebted to their caregivers for their support. They thank Mrs. Ilma Marçal Souza for her skilled technical assistance and Professor Mauro Martins Teixeira (Universidade Federal de Minas Gerais) for his support in the execution of this work.

\section{References}

1. Hughes AJ, Daniel SE, Kilford L, Lees AJ. Accuracy of clinical diagnosis of idiopathic Parkinson's disease: a clinicopathological study of 100 cases. J Neurol Neurosurg Psychiatry. 1992 Mar;55(3):181-4. https://doi.org/10.1136/jnnp.55.3.181

2. Martí MJ, Tolosa E. Parkinson disease: new guidelines for diagnosis of Parkinson disease. Nat Rev Neurol. 2013 Apr;9(4):190-1. https://doi.org/10.1038/nrneurol.2013.47

3. Lanni C, Stanga S, Racchi M, Govoni S. The expanding universe of neurotrophic factors: therapeutic potential in aging and age-associated disorders. Curr Pharm Des. 2010;16(6):698-717. https://doi.org/10.2174/138161210790883741

4. Razavi S, Nazem G, Mardani M, Esfandiari E, Salehi H, Esfahani $\mathrm{SH}$. Neurotrophic factors and their effects in the treatment of multiple sclerosis. Adv Biomed Res. 2015 Feb;4(1):53. https://doi.org/10.4103/2277-9175.151570

5. Lau LM, Breteler MM. Epidemiology of Parkinson's disease. Lancet Neurol. 2006 Jun;5(6):525-35. https://doi.org/10.1016/S1474-4422(06)70471-9

6. Tome D, Fonseca CP, Campos FL, Baltazar G. Role of Neurotrophic Factors in Parkinson's Disease. Curr Pharm Des. 2017;23(5):809-38. https://doi.org/10.2174/1381612822666161208120422
7. Mogi M, Togari A, Kondo T, Mizuno Y, Komure O, Kuno S et al. Brainderived growth factor and nerve growth factor concentrations are decreased in the substantia nigra in Parkinson's disease. Neurosci Lett. 1999 Jul;270(1):45-8. https://doi.org/10.1016/S0304-3940(99)00463-2

8. Chauhan NB, Siegel GJ, Lee JM. Depletion of glial cell line-derived neurotrophic factor in substantia nigra neurons of Parkinson's disease brain. J Chem Neuroanat. 2001 Jun;21(4):277-88. https://doi.org/10.1016/S0891-0618(01)00115-6

9. Lorigados Pedre L, Pavón Fuentes N, Alvarez González L, McRae A, Serrano Sánchez T, Blanco Lescano L et al. Nerve growth factor levels in Parkinson disease and experimental parkinsonian rats. Brain Res. 2002 Oct;952(1):122-7. https://doi.org/10.1016/S0006-8993(02)03222-5

10. Scalzo P, Kümmer A, Bretas TL, Cardoso F, Teixeira AL. Serum levels of brain-derived neurotrophic factor correlate with motor impairment in Parkinson's disease. J Neurol. 2010 Apr;257(4):540-5. https://doi.org/10.1007/s00415-009-5357-2

11. Ricci V, Pomponi M, Martinotti G, Bentivoglio A, Loria G, Bernardini $S$ et al. Antidepressant treatment restores brain-derived neurotrophic factor serum levels and ameliorates motor function in Parkinson disease patients. J Clin Psychopharmacol. 2010 Dec;30(6):751-3. https://doi.org/10.1097/JCP.0b013e3181fc2ec7 
12. Ziebell M, Khalid U, Klein AB, et al. Striatal dopamine transporter binding correlates with serum BDNF levels in patients with striatal dopaminergic neurodegeneration. Neurobiol Aging. 2012;33(2):428 e421-425. https://doi.org/10.1016/j.neurobiolaging.2010.11.010

13. Wang Y, Liu H, Du XD, Zhang Y, Yin G, Zhang BS et al. Association of low serum BDNF with depression in patients with Parkinson's disease. Parkinsonism Relat Disord. 2017 Aug;41:73-8. https://doi.org/10.1016/j.parkreldis.2017.05.012

14. Wang Y, Liu H, Zhang BS, Soares JC, Zhang XY. Low BDNF is associated with cognitive impairments in patients with Parkinson's disease. Parkinsonism Relat Disord. 2016 Aug;29:66-71. https://doi.org/10.1016/j.parkreldis.2016.05.023

15. Rocha NP, Assis F, Scalzo PL, Vieira ÉL, Barbosa IG, de Souza MS et al. Reduced Activated T Lymphocytes (CD4+CD25+) and Plasma Levels of Cytokines in Parkinson's Disease. Mol Neurobiol. 2017 Feb. https://doi.org/10.1007/s12035-017-0404-y

16. Fahn S, Elton R. Unified parkinson's disease rating scale. In: Fahn S, Marsden CD, Calne. DB, Goldstein M, eds. Recent developments in Parkinson's disease. Florham Park: Macmillan Health Care Information; 1987. Volume 2, p. 153-163.

17. Hoehn MM, Yahr MD. Parkinsonism: onset, progression and mortality. Neurology. 1967 May;17(5):427-42. https://doi.org/10.1212/WNL.17.5.427

18. Folstein MF, Folstein SE, McHugh PR. "Mini-mental state". A practical method for grading the cognitive state of patients for the clinician. J Psychiatr Res. 1975 Nov;12(3):189-98. https://doi.org/10.1016/0022-3956(75)90026-6

19. Brucki SM, Nitrini R, Caramelli P, Bertolucci PH, Okamoto IH. [Suggestions for utilization of the mini-mental state examination in Brazil]. Arq Neuropsiquiatr. 2003 Sep;61 3B:777-81. https://doi.org/10.1590/S0004-282X2003000500014

20. Dubois B, Slachevsky A, Litvan I, Pillon B. The FAB: a Frontal Assessment Battery at bedside. Neurology. 2000 Dec;55(11):1621-6. https://doi.org/10.1212/WNL.55.11.1621

21. Beato RG NR, Formigoni AP, Caramelli P. Brazilian version of the Frontal Assessment Battery (FAB): preliminary data of administration to healthy elderly. Dement Neuropsychol. 2007;1:59-65. https://doi: 10.1590/S1980-57642008DN10100010.

22. Beck AT, Ward CH, Mendelson M, Mock J, Erbaugh J. An inventory for measuring depression.
Arch Gen Psychiatry. 1961 Jun;4(6):561-71. https://doi.org/10.1001/archpsyc.1961.01710120031004

23. Silberman CD, Laks J, Capitão CF, Rodrigues CS, Moreira I, Engelhardt E. Recognizing depression in patients with Parkinson's disease: accuracy and specificity of two depression rating scale. Arq Neuropsiquiatr. 2006 Jun;64(2b 2B):407-11. https://doi.org/10.1590/S0004-282X2006000300011

24. Tumas V, Rodrigues GG, Farias TL, Crippa JA. The accuracy of diagnosis of major depression in patients with Parkinson's disease: a comparative study among the UPDRS, the geriatric depression scale and the Beck depression inventory. Arq Neuropsiquiatr. 2008 Jun;66(2a 2A):152-6. https://doi.org/10.1590/S0004-282X2008000200002

25. Ventriglia M, Zanardini R, Bonomini C, Zanetti O, Volpe D, Pasqualetti $P$ et al. Serum brain-derived neurotrophic factor levels in different neurological diseases. BioMed Res Int. 2013;2013:901082. https://doi.org/10.1155/2013/901082

26. Salehi Z, Mashayekhi F. Brain-derived neurotrophic factor concentrations in the cerebrospinal fluid of patients with Parkinson's disease. J Clin Neurosci. 2009 Jan;16(1):90-3. https://doi.org/10.1016/j.jocn.2008.03.010

27. Zoladz JA, Majerczak J, Zeligowska E, Mencel J, Jaskolski A, Jaskolska A et al. Moderate-intensity interval training increases serum brain-derived neurotrophic factor level and decreases inflammation in Parkinson's disease patients. J Physiol Pharmacol. 2014 Jun;65(3):441-8.

28. Frazzitta G, Maestri R, Ghilardi MF, Riboldazzi G, Perini M, Bertotti $G$ et al. Intensive rehabilitation increases BDNF serum levels in parkinsonian patients: a randomized study. Neurorehabil Neural Repair. 2014 Feb;28(2):163-8. https://doi.org/10.1177/1545968313508474

29. Pålhagen S, Qi H, Mårtensson B, Wålinder J, Granérus AK, Svenningsson P. Monoamines, BDNF, IL-6 and corticosterone in CSF in patients with Parkinson's disease and major depression. J Neurol. 2010 Apr;257(4):524-32. https://doi.org/10.1007/s00415-009-5353-6

30. Leverenz JB, Watson GS, Shofer J, Zabetian CP, Zhang J, Montine TJ. Cerebrospinal fluid biomarkers and cognitive performance in non-demented patients with Parkinson's disease. Parkinsonism Relat Disord. 2011;17(1):61-64. https://doi: 10.1016/j.parkreldis.2010.10.003. 